\title{
The system evaluation model of mobile navigation devices (MPD) using integrated DEMATEL approach
}

\author{
Chia-Li Lin ${ }^{\text {a }}$, Ya-Wen Yu ${ }^{\text {b, }}$, Gwo-Hshiung Tzeng ${ }^{c}$ \\ ${ }^{a}$ Department of Recreation Management, Shin Chien University, 200 University Road, Neimen, Kaohsiung, Taiwan, \\ 845 \\ ${ }^{\mathrm{b}}$ Department of Business Management, Asia University, 500 Liou-Feng Road, Wufeng District, Taichung, Taiwan, 413 \\ ${ }^{c}$ Graduate Institute of Urban Planning, College of Public Affairs, National Taipei University, 151 University Road, San \\ Shia, Taiwan, 237 \\ *Corresponding Author: yoyawin@gmail.com, linchiali0704@yahoo.com.tw
}

\begin{abstract}
The development of mobile devices (such as mobile phone) has moved into fast pace and provides multiple-functions (such as camera and GPS) and works more like a personal computer in now a days. In this study, we intend to explore the features and services needs for the next generation mobile navigation devices. In order to find future strategy for mobile navigation devices, handheld navigation devices (PND), three lithographic navigation device (Pad) and smart phones (Smart phone) mobile navigation device were included in the survey for this empirical analysis. In accordance with its competitive advantage dimension to further develop a new generation of mobile navigation device development strategy. We then recommend service development strategies based on the findings. The conclusions are a good reference for mobile navigation devices companies to apply to improve their service quality.
\end{abstract}

Keywords: Mobile navigation device, Mobile application, Location-based service (LBS), DEMATEL

\section{Introduction}

Due to advances information technology and global positioning technology, more and more users incorporate off-board mobile navigation devices inside their vehicle, such as handheld navigation device (PND) or smart phone (Smart phone), mobile annexed navigation application services (Mobile navigation Application). With more Location-Based Service (LBS) information derived from mobile commerce services; users can get information or service that they need anytime and anywhere. In addition, to meet high user demand, Mobile Customer Relationship Management(mCRM) is characterized by personalization, interactivity as well as more flexible communication that provide users with a more personalized service (Sinisalo, Salo, Karjaluoto, \& Leppäniemi, 2007). Location-Based Services System is based on development of mobile services to meet customer demands. Companies can further use land-based services to develop strategies for customer relationship management, and user' $\mathrm{s}$ geographical location information. The emergence of mobile networks and mobile devices allow GPS system to locate consumer and provide variety of services (Mathkour, 2011).

As mobile device become more popular in daily life, people can use mobile devices anytime, anywhere, and there are different types of services offered to consumer. Global Position System (GPS) become an essential device for mobile devices. Thus, mobile devices equipped with a global positioning system (Global Position System, GPS) became the basic unit equipped in nowadays.

This study attempts to explore what type of Location-Based Service that can meet the needs to different kind users in different area. Therefore, in this study, we investigated mobile user' $s$ needs and find what type of services that can be develop in the future. This study assessed the four aspects, such as Information Searching (IS), Social Networking (SN), Business Services (BS) and Security services (SS) to build mobile navigation device to improve the strategy map, we use Decision Making Trial and Evaluation Laboratory, DEMATEL to construct facets of mobile navigation device service systems / guidelines related structure, followed by the use of DEMATEL method to identify the various types of user preference for mobile navigation devices.

This study is divided into five sections, the second 
section we want to discuss about the drivers of mobile devices, the third part is research method, the fourth part we use PND, pad and smart phone as examples to evaluate, the final section is conclusion. In the end, we would like to find the key success factor when developing mobile devices..

\section{Navigation and Location based service (LBS)}

The most important concept for LBS is that to locate user' $s$ location and to provide data for developers, and then provide users appropriate service on the right time. There fore, LBS service model can be separate into User need, Location, Context and Geospial Data Processing (Jiang \& Yao, 2006). Thus, understanding users' needs and motivations for using mobile devices is important before design LBS application. At present, studies have pointed out that LBS can be applied into many aspects for example, navigation services, emergency rescue, tracking services and network services (Sadoun \& Al-Bayari, 2007).

\subsection{Demands for mobile users}

People use mobile phones and other mobile devices are no longer simply used for communication, there are various types of function incorporate in mobile devices to suit various needs. Thus, when developing mobile device, we need to consider what people needs instead of just mobile devices itself. So developer needs to know why people use mobile devices in order to develop appropriate mobile devices. In 2000 many scholars found that there are seven influence factors that may affect user' $s$ selection on application and services. They are, Pop status, emotional and social, leisure time, mobility, immediacy, as a business tool and security in seven factors that may affect the user to select different applications and services (Leung \& Wei, 2000; Savio \& Braiterman, 2007). Therefore, this study used situational value and use value of construct research framework to find the demand on mobile devices, and then measure what is most important for the user' s needs, in order to identify the needs to improve the user needs, and make improvement strategies in the future.

\section{(1) Information searching (IS)}

Location-Based Services System is linked with GPS, and information content is the key element to success, which allows user to search restaurants nearby, current traffic situation, friends' status via social networking sites, special events in stores, personal calendar, or use Internet to get different kinds of service and transmit needs just in time.
(Golob \& Regan, 2001; van den Anker \& Arnold, 1998) • Moreover, the rise of Context-Aware Computing provided users to use mobile device anytime anywhere with instant and customized information and services. For example, city sightseeing navigation application named "Guide System" was developed using to meet tourist navigation needs. Guide System is equipped with wireless technology and situational awareness computing technology, along with hypermedia management (Hypermedia Management is a way to get sound, images and video files and it can be freely accessed on the World Wide Standards) function, the system will use the personal information (such as: age, interests, etc.) to send the current environmental information through mobile devices (such as: location, time, etc.), to provide information that tourists need. South Korean researchers have developed a set of OYT System (Optimize Your Time System), which incorporate Seoul train timetable that is build-in with GPS device, and calculates the shortest distance and time to travel (Kim, Lee, Oh, \& Choi, 2009). As GPS became more and more essential for mobile devices, a variety of real-time traveling information is provided for users (Herrera et al., 2010). Based on above studies, scholars believe that through computing technology, there is a demand for personalized system in the market, and can become user' s personal secretary equipment (Anker \& Arnold, 1998; Golob \& Regan, 2001). Therefore, this study will collect information and broken down into criteria such as life demand information services, secretarial services operations, navigation information services and travel information services to analyze the service preference.

\section{(2) Social networking ( $\mathrm{SN})$}

A study from an Australian scholar specializing in the use of mobile phone content services, have divided information and motivation for young people in Australia on a mobile phone service scenarios into three parts: (1) business activities, (2) personal services and social life and (3) communication tool, we can see that mobile device users to socialize and communicate is very important part. Communication become easy with mobile devices, user can be connected with friends anytime, anywhere. Enterprises can get connected with business partners more easily using social media and establish more solid trust and maintain better relationship with customers and business partners (O'Doherty, Rao, \& Mackay, 2007). The more popularity of mobile devices and mobile networks Communications, the less distance between users (Xu, Chin, Wang, \& Zhang, 
2011). Social media gives advantage that user can get linked with friends through same geographic sites. This changes the way how people connect with each other and life style, users can meet new friends simply with online social network (Backstrom, Sun, \& Marlow, 2010; Wilson, 2012). Therefore, this study developed criteria into Information Communication Service (SN1), Action Link Services (SN2), Networking Maintain Function (SN3) and Population Attributable Function (SN4) for a better understanding of users' social networking needs preferences.

\section{(3) Business services (BS)}

Location based service is provided through mobile devices, as users can get connected on Internet, E-commerce changed to M-commerce, low cost is one advantage of $\mathrm{M}$-commerce. This high mobility gives consumers buy good online and get discount coupon (Dholakia \& Dholakia, 2004) just like when they use e-commerce $\circ$ Mobile commerce can include different kinds of service, which include, products, service, electronic receipt, banking service and other type of payment services. Above all, mobile advertising has been the hottest service for commercial marketing, The targeted mobile advertising, TMAS become the most popular commercial platform that provide enterprises information about consumers and vice versa (de Reuver \& Haaker, 2009; Li \& Du, 2012).

\section{(4) Security services (SS)}

Since the United States open civil to use GPS, E911 bill stated all cellular phone must have GPS positioning function, so it can track the user when calling 911 for help. So later many countries have begun to implement similar laws, such as the EU E112, Japan's E110 / 119 bill. (Sadoun \& Al-Bayari, 2007; Theiss, Yen, \& Ku, 2005) •If the user is in a high state of emergency : GPS system can track and update the location of user and rescue team and the user can also use the action device for rapid decision to reduce uncertain situation (Gummerus \& Pihlström, 2011) • And as Internet become more and more essential in household, electronic equipment can connect to the Internet and mobile phones can help to monitoring home anytime, anywhere. (Al-Ali, El-Hag, Bahadiri, Harbaji, \& Ali El Haj, 2011; Hsu, Yang, \& Wu, 2010; Kim, Lee, Kim, \& Kim, 2012; Möller, Krebber, \& Smeele, 2006). Therefore, this study will preserve the security requirements into four criteria: location tracking function (SS1), emergency rescue function (SS2), anti-theft security features (SS3) and Home Monitoring (SS4), in order to further understand the user for security preservation requirements.

\section{Research Method}

\subsection{DEMATEL technique}

In this research study, we have used the DEMATEL method as our analyzing method. The DEMATEL method can be used to construct interrelations among criteria and has been widely used to solve problems of interdependence among variables/criteria. The DEMATEL method has also restricted the relations that reflect characteristics within an essential systematic and developmental trend (Tzeng et al., 2007). In other words, when making the decision, the decision-maker has to consider the criteria (first-tier criteria and sub-criteria) in detail for the interrelations between them, then find out the key criteria, modify them and then the whole performance of satisfaction will be improved. For our background knowledge to utilize and understand how previous studies used the DEMATEL method, we found several studies that used the DEMATEL method to evaluate and solve the problem in their study (Wu et al., 2010; Tzeng et al., 2007; Chiu et al., 2006; Wu, 2007; Sun, 2011). According to Chiu et al. (2006), the DEMATEL method is used to build a relative relationship of decision factors. The relationship supports a multi-level viewpoint to plan a strategy which conforms to actual situations and a competitive environment. The steps of the DEMATEL method are described as follows: (1) Calculate the initial average matrix, (2) Calculate the direct influence matrix, (3) Calculate the indirect influence matrix, (4) Calculate the full influence matrix, (5) Determines the network relationship map (NRM).

\section{(1) Calculate the initial average matrix}

Rate the influence from respondent according to an integer scale ranging by four levels, where the scores of 0,1 , 2, 3, and 4 represent No influence, Low influence, Moderate influence, High influence, and Very high influence, respectively. As the data shows in Table 2, the influence that "IS" to "BS" is 2.547 , which means "medium influence". On the other hand, the influence that "BS" to "IS" is 2.474 , also means "medium influence".

Table 2 The average influence matrix A (Original)

\begin{tabular}{cccccc}
\hline Aspects & IS & SN & BS & SS & Total \\
\hline Information searching (IS) & 0.000 & 2.558 & $\mathbf{2 . 5 4 7}$ & 2.505 & 7.611 \\
Social networking (SN) & 2.632 & 0.000 & 2.421 & 2.484 & 7.537 \\
Business services (BS) & $\mathbf{2 . 4 7 4}$ & 2.295 & 0.000 & 2.316 & 7.084 \\
Security services (SS) & 2.547 & 2.421 & 2.200 & 0.000 & 7.168 \\
\hline Total & 7.653 & 7.274 & 7.168 & 7.305 & - \\
\hline
\end{tabular}

\section{(2) Calculate the direct influence matrix}

From Table 2, we processed the "Original influence matrix" $(A)$ by Equations (1) and (2) and got the "direct influence matrix" $(\boldsymbol{D})$. As illustrated in Table 3, the 
diagonal items of $\boldsymbol{D}$ are all 0 ; the sum of a row is 1, at most. Then we got Table 3 by adding up the rows and columns. In Table 4, the sum of rows and columns for "IS" is 1.994, which is the most important influence aspect. On the other hand, the sum of rows and columns for "BS" is 1.862 , which is the least important influence aspect.

$$
\boldsymbol{D}=s \boldsymbol{A}, \quad s>0
$$

where:

$$
s=\min _{i, j}\left[1 / \max _{1 \leq i \leq n} \sum_{j=1}^{n} a_{i j}, 1 / \max _{1 \leq j \leq n} \sum_{i=1}^{n} a_{i j}\right], \quad i, j=1,2, \ldots, n
$$

and $\quad \lim _{m \rightarrow \infty} \boldsymbol{D}^{m}=[0]_{n \times n}, \quad$ where $\quad \boldsymbol{D}=\left[x_{i j}\right]_{n \times n}, \quad$ when $0<\sum_{j=1}^{n} x_{i j} \leq 1$ or $0<\sum_{i=1}^{n} x_{i j} \leq 1$, and at least one $\sum_{j=1}^{n} x_{i j}$ or $\sum_{i=1}^{n} x_{i j}$ equal one, but not all. So we can guarantee $\lim _{m \rightarrow \infty} \boldsymbol{D}^{m}=[0]_{n \times n}$.

Table 3 The direct influence matrix $D$

\begin{tabular}{cccccc}
\hline Aspects & IS & SN & BS & SS & Total \\
\hline Information searching (IS) & 0.000 & 0.334 & 0.333 & 0.327 & 0.994 \\
Social networking (SN) & 0.344 & 0.000 & 0.316 & 0.325 & 0.985 \\
Business services (BS) & 0.323 & 0.300 & 0.000 & 0.303 & 0.926 \\
Security services (SS) & 0.333 & 0.316 & 0.287 & 0.000 & 0.937 \\
\hline Total & 1.000 & 0.950 & 0.937 & 0.955 & - \\
\hline
\end{tabular}

Table 4 The degree of direct influence

\begin{tabular}{ccccc}
\hline Aspects & $\begin{array}{c}\text { Sum of } \\
\text { rows }\end{array}$ & $\begin{array}{c}\text { Sum of } \\
\text { columns }\end{array}$ & $\begin{array}{c}\text { Sum of rows } \\
\text { and columns }\end{array}$ & $\begin{array}{c}\text { Importance } \\
\text { of influence }\end{array}$ \\
\hline Information searching (IS) & 0.994 & 1.000 & $\mathbf{1 . 9 9 4}$ & 1 \\
Social networking (SN) & 0.985 & 0.950 & 1.935 & 2 \\
Business services (BS) & 0.926 & 0.937 & $\mathbf{1 . 8 6 2}$ & 4 \\
Security services (SS) & 0.937 & 0.955 & 1.891 & 3 \\
\hline
\end{tabular}

\section{(3) Calculate the indirect influence matrix}

The indirect influence matrix can be derived from Equation 3.

$$
\boldsymbol{I D}=\sum_{i=2}^{\infty} \boldsymbol{D}^{i}=\boldsymbol{D}^{2}(\boldsymbol{I}-\boldsymbol{D})^{-1}
$$

Table 5 The indirect influence matrix

\begin{tabular}{cccccc}
\hline Aspects & IS & SN & BS & SS & Total \\
\hline Information searching (IS) & 6.261 & 5.943 & 5.875 & 5.968 & 24.047 \\
Social networking (SN) & 6.133 & 5.989 & 5.845 & 5.931 & 23.898 \\
Business services (BS) & 5.856 & 5.643 & 5.648 & 5.663 & 22.810 \\
Security services (SS) & 5.905 & 5.688 & 5.635 & 5.786 & 23.014 \\
\hline Total & 24.155 & 23.263 & 23.003 & 23.348 & - \\
\hline
\end{tabular}

\section{(4) Calculate the full influence matrix}

The full influence matrix $T$ can be derived from Equations (4) or (5). Table 6 is the calculated full influence matrix. As shown in Table 6 , the full influence matrix $T$ consists of multiple elements, indicated as Equation (6).
The sum vector of the row value is $\{d\}$. The sum vector of the column value. The sum vector of the row value plus the column value is $\left\{d_{i}+r_{i}\right\}$, which means the full influence of the matrix $T$. As the sum of the row value plus the column value $\left\{d_{i}+r_{i}\right\}$ is higher, the correlation of the dimension or criterion is stronger. The sum of the row value minus the column value is $\left\{\boldsymbol{d}_{i}-\boldsymbol{r}_{i}\right\}$, which means the net influence relationship. If $\boldsymbol{d}_{\boldsymbol{i}}-\boldsymbol{r}_{\boldsymbol{i}}>0$, it means the degree of influencing others is stronger than the degree of being influenced. As illustrated in Table 7, the IS has the highest degree of full influence $\left(d_{3}+r_{3}=\mathbf{5 0 . 1 9 5}\right)$, follow by the highest degree of net influence is BS $\left(d_{2}-r_{2}=\mathbf{0 . 6 7 0}\right)$.as well as the highest degree of net influence $\left(d_{2}-r_{2}=0.743\right)$. The order of the other net influences is listed as follows: the IS $\left(d_{1}-r_{1}=\right.$ $-0.114)$, the BS $\left(d_{3}-r_{3}=-0.203\right)$, and the last one SS $\left(d_{4}-r_{4}=-0.353\right)$.

$$
\begin{gathered}
\boldsymbol{T}=\boldsymbol{D}+\boldsymbol{I} \boldsymbol{D}=\sum_{i=1}^{\infty} \boldsymbol{D}^{i} \\
\boldsymbol{T}=\sum_{i=1}^{\infty} \boldsymbol{D}^{i}=\boldsymbol{D}(\boldsymbol{I}-\boldsymbol{D})^{-1} \\
\boldsymbol{T}=\left[t_{i j}\right], \quad i, j=1,2, \ldots . n \\
d=d_{n \times 1}=\left[\sum_{j=1}^{n} t_{i j}\right]_{n \times 1} \\
r=r_{n \times 1}=\left[\sum_{i=1}^{n} t_{i j}\right]_{1 \times n}
\end{gathered}
$$

Table 6 The full influence matrix $(T)$

\begin{tabular}{cccccc}
\hline Aspects & IS & SN & BS & SS & Total \\
\hline Information searching (IS) & 6.261 & 6.277 & 6.208 & 6.295 & 25.041 \\
Social networking (SN) & 6.477 & 5.989 & 6.161 & 6.256 & 24.883 \\
Business services (BS) & 6.179 & 5.943 & 5.648 & 5.966 & 23.736 \\
Security services (SS) & 6.238 & 6.004 & 5.922 & 5.786 & 23.950 \\
\hline Total & 25.155 & 24.213 & 23.939 & 24.303 & - \\
\hline
\end{tabular}

Table 7 The degree of full influence

\begin{tabular}{ccccc}
\hline Aspects & $\{\boldsymbol{d}\}$ & $\{\boldsymbol{r}\}$ & $\{\boldsymbol{d}+\boldsymbol{r}\}$ & $\{\boldsymbol{d}-\boldsymbol{r}\}$ \\
\hline Information searching (IS) & 25.041 & 25.155 & $\mathbf{5 0 . 1 9 5}$ & -0.114 \\
Social networking (SN) & 24.883 & 24.213 & 49.096 & $\mathbf{0 . 6 7 0}$ \\
Business services (BS) & 23.736 & 23.939 & $\mathbf{4 7 . 6 7 5}$ & -0.203 \\
Security services (SS) & 23.950 & 24.303 & 48.253 & -0.353 \\
\hline
\end{tabular}

\section{(5) Determines the network relationship map (NRM)}

According to the aspects/criteria defined in Table 1, some experts were invited to discuss the relationships and influence levels of criteria under the same aspects/criteria and to score the relationship and influence among the criteria based on the DEMATEL technique. The aspects/criteria are divided into different types, so the experts could answer the questionnaire in areas/fields with which they were familiar. The influence matrix can be derived from Eq. (9). As Table 8 shows the net influence matrix. Equation (9) can produce the net full influence matrix, as illustrated in Table 9. Using the values of $(\boldsymbol{d}+\boldsymbol{r})$ 
and $(\boldsymbol{d}-\boldsymbol{r})$ in Table 8 as the $\mathrm{X}$ value and $\mathrm{Y}$ value, respectively, the NRM can be drawn as shown in Figure 1. Figure 1 illustrates that the $\mathrm{SN}$ aspect is the major dimension with a net influence, while the SS aspect is the major dimension being influenced. The IS aspect is the dimension with the highest full influence, while the SS is the one with the smallest full influence aspect.

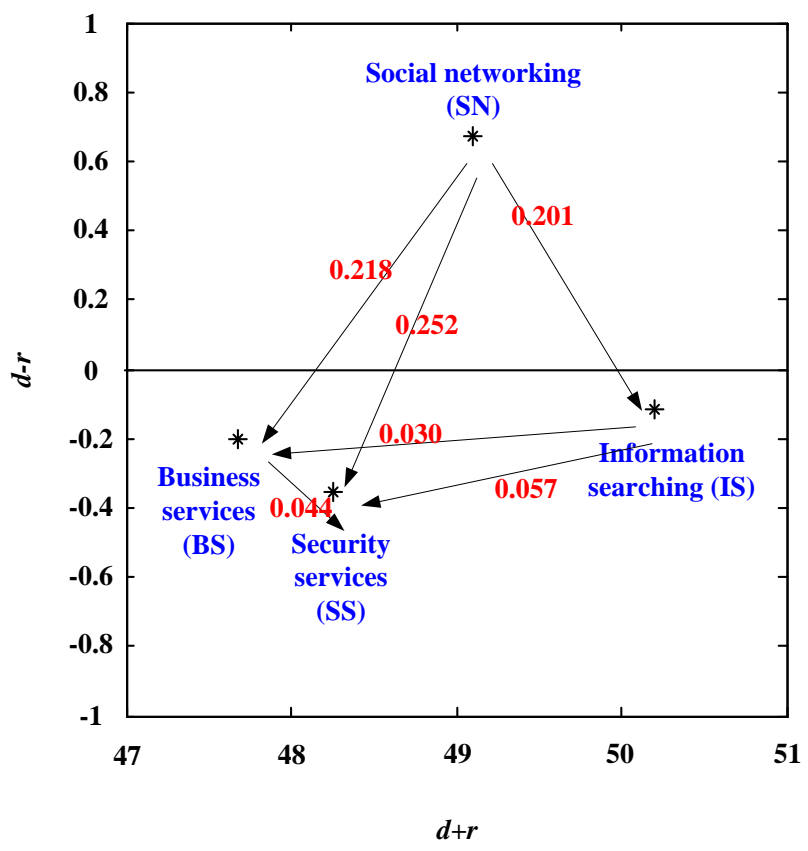

Figure 1 The inter-relationship among aspects $(\boldsymbol{d}+\boldsymbol{r} / \boldsymbol{d}-\boldsymbol{r})$

\section{Conclusions}

According to the aspects/criteria, there are four aspects, such as Information search (IS), Social Networking (SN), Business Activities (BS) and the preservation of the security services (SS) and experts were invited to discuss the relationships and influence levels of criteria under the same aspects/criteria and to score the relationship and influence among the criteria based on the DEMATEL technique. The aspects/criteria are divided into different types, so the experts could answer the questionnaire in areas/fields with which they were familiar. The influence matrix can be derived from Eq. (9). Which in the four aspects, Information search (IS), Social networking (SN) Business Activities (BS) aspects are more influential, while the $\mathbf{S S}$ aspect is the major dimension being influenced. The IS aspect is the dimension with the highest full influence, while the SS is the one with the smallest full influence aspect.

\section{References}

(1) Al-Ali, A. R., El-Hag, A., Bahadiri, M., Harbaji, M., \& Ali El Haj, Y. 2011. Smart Home Renewable Energy Management System. Energy ProcedIS, 12: 120-126.

(2) Anker, F. W. G., \& Arnold, A. G. 1998. The usefulness of mobile multimedIS communications: a case study. Displays, 18(4): 193-197.

(3) Backstrom, L., Sun, E., \& Marlow, C. 2010. Find me if you can: improving geographical prediction with socISl and spatISl proximity. Paper presented at the Proceedings of the 19th international conference on World wide web.

(4) Chiu, Y.J., Chen, H. C., Tzeng, G.H., \& Shyu, J. Z. (2006). Marketing strategy based on customer behavior for the LCD-TV. International Journal of Management and Decision Making, 7(2/3), 143-165.

(5) de Reuver, M., \& Haaker, T. 2009. Designing vISble business models for context-aware mobile services. Telematics and Informatics, 26(3): 240-248.

(6) Dholakia, R. R., \& Dholakia, N. 2004. Mobility and markets: emerging outlines of m-commerce. Journal of Business Research, 57(12): 1391-1396.

(7) Golob, T. F., \& Regan, A. C. 2001. Impacts of information technology on personal travel and commercial vehicle operations: research challenges and opportunities. Transportation Research Part C: Emerging Technologies, 9(2): 87-121.

(8) Gummerus, J., \& Pihlström, M. 2011. Context and mobile services' value-in-use. Journal of Retailing and Consumer Services, 18(6): 521-533.

(9) Herrera, J. C., Work, D. B., Herring, R., Ban, X., Jacobson, Q., \& Bayen, A. M. 2010. Evaluation of traffic data obtained via GPS-enabled mobile phones: The Mobile Century field experiment. Transportation Research Part C: Emerging Technologies, 18(4): 568-583.

(10) Hsu, C.-L., Yang, S.-Y., \& Wu, W.-b. 2010. 3C intelligent home appliance control system - Example with refrigerator. Expert Systems with Applications, 37(6): 4337-4349.

(11) Jiang, B., \& Yao, X. 2006. Location-based services and GIS in perspective. Computers, Environment and Urban Systems, 30(6): 712-725.

(12) Kim, H., Lee, S. K., Kim, H., \& Kim, H. 2012. Implementing home energy management system with UPnP and mobile applications. Computer Communications.

(13) Kim, N., Lee, H. S., Oh, K. J., \& Choi, J. Y. 2009. Context-aware mobile service for routing the fastest 
subway path. Expert Systems with Applications, 36(2): 3319-3326.

(14) atifications of the cellular phone. Journalism \& Mass Communication Quarterly, 77(2): 308-320.

(15)Li, K., \& Du, T. C. 2012. Building a targeted mobile advertising system for location-based services. Decision Support Systems.

(16) Möller, S., Krebber, J., \& Smeele, P. 2006. Evaluating the speech output component of a smart-home system. Speech Communication, 48(1): 1-27.

(17) Mathkour, H. I. 2011. A GPS-based Mobile Dynamic Service Locator System. Applied Computing and Informatics, 9(2): 95-106.

(18) O'Doherty, K., Rao, S., \& Mackay, M. M. 2007. Young AustralISns' perceptions of mobile phone content and information services: an analysis of the motivations behind usage. Young Consumers: Insight and Ideas for Responsible Marketers, 8(4): 257-268.

(19) Savio, N., \& Braiterman, J. 2007. Design sketch: The context of mobile interaction. Proceedings of MobileHCI 2007: 284-286.

(20) Theiss, A., Yen, D. C., \& Ku, C. Y. 2005. Global Positioning Systems: an analysis of applications, current development and future implementations. Computer Standards \& Interfaces, 27(2): 89-100.

(21) Tzeng, G. H., ChISng, C. H., \& Li, C. W. 2007. Evaluating intertwined effects in e-learning programs: A novel hybrid MCDM model based on factor analysis and DEMATEL. Expert Systems with Applications, 32(4): 1028-1044.

(22) van den Anker, F. W. G., \& Arnold, A. G. 1998. The usefulness of mobile multimedIS communications: a case study. Displays, 18(4): 193-197.

(23) Wilson, M. W. 2012. Location-based services, conspicuous mobility, and the location-aware future. Geoforum.

(24) Wu, W. W., \& Lee, Y. T. 2007. Developing global managers' competencies using the fuzzy DEMATEL method. Expert Systems with Applications, 32(2): 499-507.

(25) Xu, B., Chin, A., Wang, H., \& Zhang, L. 2011. SocISl linking and physical proximity in a mobile location-based service. Paper presented at the Proceedings of the 1 st international workshop on Mobile location-based service. 